\title{
Scale-dependent predator-prey interactions: the aggregative response of seabirds to prey under variable prey abundance and patchiness
}

\author{
Per Fauchald*, Kjell Einar Erikstad \\ Department of Biology, Faculty of Science, University of Tromsø, 9037 Tromsø, Norway \\ and
}

Norwegian Institute for Nature Research, Division of Arctic Ecology, The Polar Environmental Center, 9296 Tromsø, Norway

\begin{abstract}
The aggregative response of seabirds to their prey has frequently been measured through their spatial coherence during ship board surveys. In this study, we investigate the aggregative response of murres Uria spp. to capelin Mallotus villosus in relation to yearly changes in capelin abundance and patchiness from a 9 yr data set collected in the Barents Sea. A recent analysis on the spatial distribution of capelin and murres in the Barents Sea reported a hierarchical patch structure, whereby small-scale patches were nested within patches at larger scales. In the present study we carry out similar analyses for each of the 9 years. During the 9 yr period, the estimated total biomass of capelin varied between 100000 and $7300000 \mathrm{t}$. We identified 2 hierarchical levels of patchiness with characteristic scales of 200 to $300 \mathrm{~km}$ and $70 \mathrm{~km}$ respectively. We found close relationships between yearly variation in capelin abundance, capelin patchiness and the concordance between capelin and murres at both levels. The patchiness of capelin, as measured by the first-order spatial autocorrelation, increased with increasing capelin abundance at the large-scale level, and there was a similar tendency at the small-scale level. At the large-scale level, the spatial concordance between murres and capelin increased with both increasing capelin density and increasing capelin patchiness. At the small-scale level, the concordance between murres and capelin increased with increasing capelin patchiness. Our results suggest that increased prey patchiness and increased prey abundance enhance the possibility of murres finding satisfactory capelin concentrations. The reduction in prey patchiness with low prey abundance might force predators to switch to other prey items, and might therefore have a stabilizing effect on predator-prey interactions.
\end{abstract}

KEY WORDS: Spatial distribution $\cdot$ Hierarchical patch structure $\cdot$ Capelin $\cdot$ Mallotus villosus $\cdot$ Murre $\cdot$ Uria spp. Barents Sea

Resale or republication not permitted without written consent of the publisher

\section{INTRODUCTION}

One important topic in the study of interactions between predators and prey is the aggregative response of predators to prey (Hassell \& May 1973, 1974, Murdoch \& Oaten 1975, 1989). The aggregative response is a measure of the spatial and temporal overlap between concentrations of predators and their prey

*E-mail: per.fauchald@nina.no
(Hassell \& May 1974) and depends on several aspects of predator-prey interactions (Sih 1984). First, it depends on the tendencies of predators to congregate at high prey densities and the tendency of prey to avoid areas with a high risk of predation. Secondly, it depends on the proportion of predators foraging on the specific prey item. Thus, the aggregative response of predators to prey is linked to the consumption of prey through the predator's search efficiency and switching between prey items. How these factors change as a function of abundance and spatial distribution of prey 
is important when elucidating the stability of predatorprey interactions (Murdoch \& Oaten 1975).

Over-exploitation and large-scale fluctuations in ocean climate can cause dramatic changes in the abundance of marine pelagic schooling fish populations (e.g. Hamre 1994), which are important prey for seabirds. Fluctuations in the abundance and availability of preferred prey in turn affect seabird abundance (Schreiber \& Schreiber 1984, Vader et al. 1990, Veit et al. 1996, Montevecchi \& Myers 1997), demography (Aebischer et al. 1990, Anker-Nilssen 1992, Chastel et al. 1993, Guinet et al. 1998) and activity and foraging strategies (Monaghan et al. 1994, Uttley et al. 1994). The aggregative response of seabirds to their prey has frequently been measured by the spatial concordance between their densities during ship board surveys (reviewed in Hunt 1990). The results from these studies are highly variable. Some studies report weak or ephemeral correlations (Woodby 1984, Obst 1985, Heinemann et al. 1989, Veit et al. 1993, Decker \& Hunt 1996, Pakhomov \& McQuaid 1996), while others report strong correlations (Schneider \& Piatt 1986, Ryan \& Cooper 1989, Piatt 1990, Mehlum et al. 1999, Fauchald et al. 2000). Yet, to our knowledge, no studies have so far explored how year-to-year variation in prey abundance and spatial distribution affects the aggregative response of seabirds to prey.

The variability in the observed correlation between seabirds and prey has been attributed to the effect of measurement scale (e.g. Russell et al. 1992, Logerwell $\&$ Hargreaves 1996). This is because the aggregative response depends on responses and counter responses at several different scales (Rose \& Leggett 1990, Russell et al. 1992, Fauchald et al. 2000). At the large scale, one would expect predators to occupy the same general areas as their prey, forming a positive concordance (e.g. Rose \& Leggett 1990). Accordingly, given that other prey items do not have the same spatial distribution, the large-scale concordance will mainly reflect the proportion of predators actually foraging on the specific prey item. At smaller scales, however, one can expect the concordance to be determined by the predators search efficiency relative to the escape abilities of prey (e.g. Sih 1984, Rose \& Leggett 1990).

The spatial distribution of pelagic schooling fish and krill can be described as a complex hierarchical patch system, whereby patches at small scales are congregated within patches at larger scales, forming a nested hierarchy (Murphy et al. 1988, Kotliar \& Wiens 1990, Rose \& Leggett 1990, Fauchald et al. 2000). For example, Fauchald et al. (2000) described 3 levels of patchiness of murres Uria spp. and capelin Mallotus villosus in the Barents Sea. At a large scale, they found similar and overlapping patches of capelin and murres with a characteristic scale of more than $300 \mathrm{~km}$. Within these large-scale patches they found similar and overlapping medium-scale patches with a characteristic scale of about $50 \mathrm{~km}$. Finally, within the mediumscale patches they found similar but non-overlapping patches with a characteristic scale of a few kilometers. In a recent theoretical study on foraging in a hierarchical patch system, Fauchald (1999) found that the search efficiency of a predator might be highly influenced by the distribution and abundance of prey items. The main predictions from the model can be summarized as follows: (1) reduced prey abundance will reduce the information flow to the predator and consequently the ability of the predator to track the system; (2) a reduced difference in the density between patches at different hierarchical levels reduces the possibilities of being able to discriminate between them, and hence reduces the predator's ability to track the system. In other words, a well-structured patch system with high prey abundance will greatly enhance the predator's search efficiency.

In this study we explore the effects of year-to-year changes in capelin abundance and spatial pattern on the aggregative response of murres in the Barents Sea. Observations were made during the spawning migration of capelin (late January to early March) each year from 1986 to 1994 . The total biomass of capelin varied considerably during the study period, from $100000 \mathrm{t}$ in 1987 to $7300000 \mathrm{t}$ in 1991 (Anonymous 1997). Spatial analyses were performed according to Fauchald et al. (2000). Each hierarchical level of patchiness is analysed separately, starting at the largest scale limited by the extent of the study area. The patchiness of capelin is measured as the first-order spatial autocorrelation. In accordance with the model of Fauchald (1999), we expect that both decreased capelin abundance and decreased capelin patchiness reduce the search efficiency of murres. Furthermore, we suggest that the spatial concordance between murres and capelin at small spatial scales reflects search efficiency directly, while the concordance at larger scales reflects search efficiency indirectly through the profitability of capelin relative to other prey items. We therefore expect that reduced search efficiency concurrent with decreased capelin patchiness and abundance is reflected in a reduced spatial concordance between murres and capelin, irrespective of scale.

\section{MATERIALS AND METHODS}

Study area. The Barents Sea is a continental shelf and an important nursery and feeding area for commercial fish species such as herring Clupea harengus, capelin Mallotus villosus and cod Gadus morhua (Loeng 1989). Three main water masses are found in 

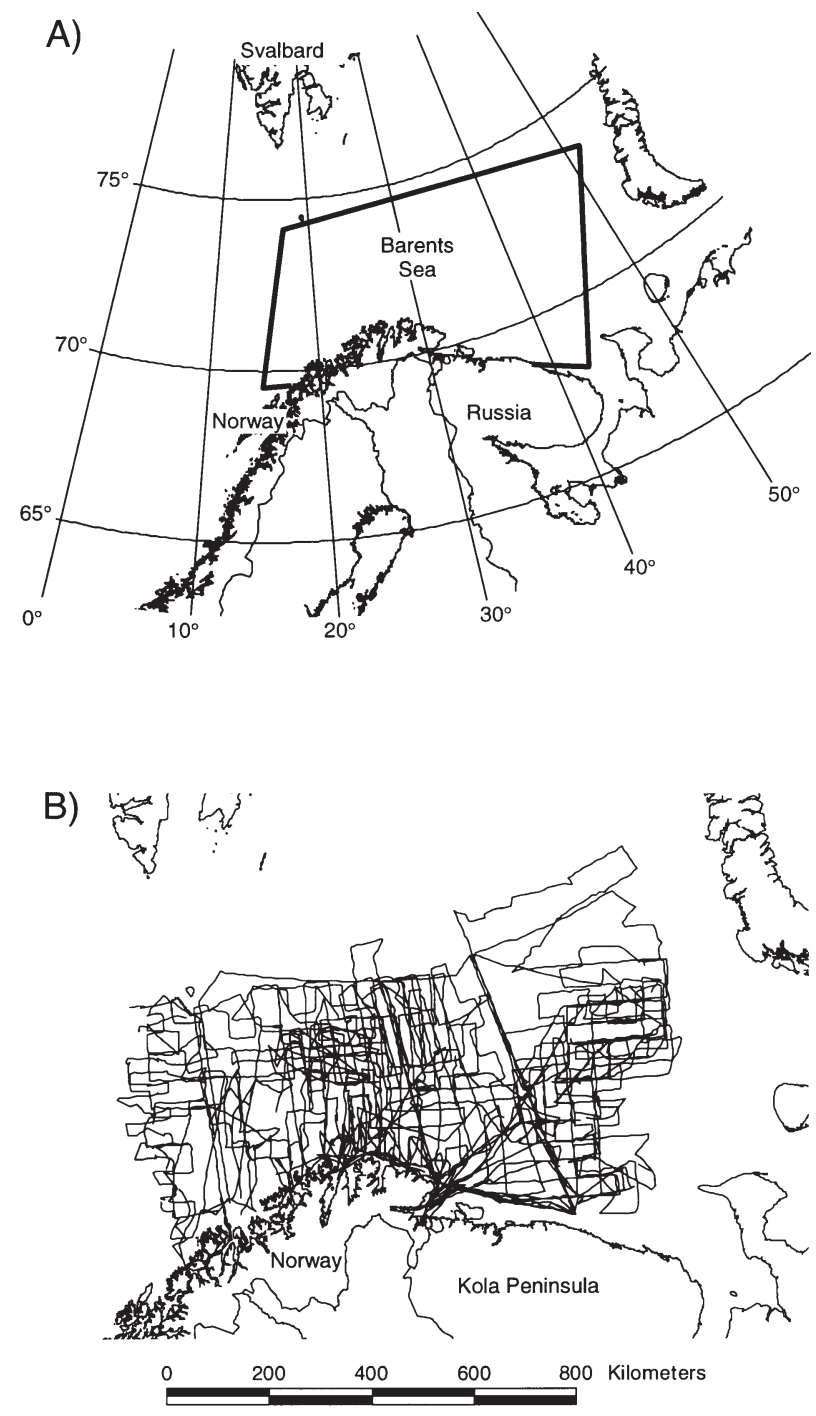

Fig. 1. (A) Study area; (B) position of transects conducted during the surveys in January to March 1986-1994

the Barents Sea (Loeng 1989): Norwegian coastal water, Atlantic water and Arctic water. The warm and high-salinity Atlantic water is in the south-western part, the low-salinity coastal water is close to the Russian and Norwegian coast, and Arctic water is in the northern and north-eastern part. The polar front is formed in the area where the Atlantic and Arctic waters meet (Loeng 1989).

Capelin is an important prey for both breeding and non-breeding murres in the area (Belopol'skii 1957, Furness \& Barrett 1985, Erikstad \& Vader 1989, Erikstad et al. 1990, Barrett et al. 1997, Fauchald et al. 2000). Capelin overwinter close to the polar front on the Atlantic side (Gjøsæter 1998). In January, maturing capelin start a spawning migration to the coast of northern Norway and the Kola Peninsula, where they spawn in March to April (Gjøsæter 1998). After spawning, the majority of the spawning stock dies. The large fluctuations in the stock of capelin in the Barents Sea during the last 2 decades have been attributed to a complex interaction between predation on capelin larvae from juvenile herring (Gjøsæeter \& Bogstad 1998, Huse \& Toresen 2000) and variable growth and age at maturity (Gjøsæter 1998). Murres are among the most common seabirds wintering in the area (Erikstad et al. 1990). Both common murres Uria aalge and thickbilled murres $U$. lomvia are found, but the latter is probably the far most numerous of the two during winter (e.g. Fauchald et al. 2000). Both species pursue and capture prey items underwater, and are able to dive to depths of at least $100 \mathrm{~m}$ (Piatt \& Nettleship 1985, Burger \& Simpson 1986).

Data collection. Observations were made during regular winter cruises conducted by the Norwegian Institute of Marine Research in the Barents Sea during the period January to March from 1986 to 1994 (Fig. 1). Data from 1993 has been published elsewhere (Fauchald et al. 2000).

Personnel from the Norwegian Institute of Marine Research made acoustic/trawl survey estimates of the densities of different fish species using standard methods (MacLennan \& Simmonds 1992). On the basis of echo integrator values and trawl hauls every 60 to $75 \mathrm{~km}$, the integrator values were assigned to different fish categories every $9260 \mathrm{~m}$ (5 n miles). We used the relative area density, $\mathrm{s}_{\mathrm{A}}$ (echo density per square nautical mile $\equiv 3.43 \mathrm{~km}^{2}$ ), assigned to capelin as an index of capelin density.

During the acoustic surveys, murres were counted continuously from the bridge (12 $\mathrm{m}$ above sea level) while the vessel was steaming at a mean speed of $18.5 \mathrm{~km} \mathrm{~h}^{-1}$. All birds seen within an arc of $300 \mathrm{~m}$ extending from directly ahead to $90^{\circ}$ to one side of the ship were counted. Only birds on the water were included in the analyses. Counts were made during daylight, but were interrupted by bad weather and reduction in the speed of the boat when trawling. Due to short day lengths, the sample size of murre observations was smaller than the sample size of capelin. Common and thick-billed murres are difficult to discriminate, and only those seen close to the ship were identified to species. Of a total count of 31455 birds, 14000 were identified, and of these $96 \%$ were thickbilled murres. Common and thick-billed murres have been observed feeding on capelin in mixed flocks in the area (Erikstad \& Vader 1989). Both species are therefore treated together and referred to as murres.

Data on sea-surface salinity (SSS) and sea-surface temperature (SST) were obtained from the International Council for the Exploration of the Sea (ICES) database for the relevant time periods. These data 
were relatively evenly distributed across the study area and are presented as IDW (interpolated distance weighting) maps using ArcView ${ }^{\circledR}$ GIS software and mean values for each year.

Spatial analyses. Separate nested spatial analyses were made for each year according to the method described by Fauchald et al. (2000). The method is designed to study patch structures at different hierarchical levels. When studying a structure at a particular scale, the method reduces noise generated from structures at both smaller and larger scales. Aggregating the data at a proper scale minimizes noise generated from smaller-scale structures; using a nested approach minimizes noise generated from larger-scale structures. The number of levels that it is possible to analyze is limited by the resolution of the data and the extent of the study area. The resolution of data was constrained by the minimum scale at which capelin densities was calculated during the surveys. Thus, the analyses at the smallest scale were performed on data aggregated on a spatial scale of $9260 \mathrm{~m}$ ( $5 \mathrm{n}$ miles). The extent of the study area (Fig. 1) constrained the possibility of detecting patterns on a scale larger than about 300 to $400 \mathrm{~km}$. For the analyses at the largest scale we chose to work on data aggregated over $37 \mathrm{~km}(4 \times 5 \mathrm{n}$ miles $)$. As a consequence of these constraints, it was possible to investigate a maximum of 2 levels of patchiness.

First, data were analyzed for large-scale spatial patterns. Data were aggregated (see Fauchald et al. 2000) on a large scale (diameter $=37 \mathrm{~km}$; time window $=6 \mathrm{~h}$ ), and autocorrelogram analyses were performed on the aggregated data set. As statistics we used Moran's I index (see Legendre \& Fortin 1989). Generally, for a spatial patchy pattern, the first-order autocorrelation is positive and decreases over increasing distances. The $x$-intercept of the autocorrelation function indicates the characteristic scale of a spatial structure. Because the spatial pattern changes over time, the maximum time lag we allowed when analysing the spatial structure was $10 \mathrm{~d}$ (see Fauchald et al. 2000).
To identify the large-scale structures of capelin, observations with the lowest capelin densities were repeatedly excluded until the first- and/or secondorder autocorrelation for each remaining separate area was low $(I<0.1)$. The remaining areas were defined as large-scale capelin structures. In cases where no largescale patterns of capelin were found, we removed all continuous areas with zero densities such that only observations with non-zero capelin densities and adjacent observations with zero densities were kept.

Small-scale analyses were performed within the defined large-scale structures by computing the autocorrelation functions within each remaining area with respect to murres and capelin at the finest resolution (9260 m). Only large-scale structures with a sufficient number of observations were included in the analyses. The maximum time lag we allowed for inclusion of data in these analyses was $3 \mathrm{~d}$.

Extreme values are likely to cause erratic and skewed structure functions in the analyses of the spatial distribution of fishes and seabirds (e.g. Maravelias et al. 1996, Fauchald et al. 2000). Furthermore, differential ranges in the predictor variable will affect the correlation coefficient. Thus, to keep the densities of murres and capelin within a constant range, we chose to work on relative rank values. Accordingly, for each year, the data were rank-transformed and divided by the sample size before entering the correlogram analyses.

To study the relationship between total density, spatial distribution and overlap between predator and prey, we used the $\log _{10}$ mean density as an index of total density, the first-order autocorrelation as an index of patchiness, and the first-order cross-correlation as an index of spatial overlap.

\section{RESULTS}

Descriptive statistics for the data on capelin and murre aggregated at the minimum scale are given in

Table 1. Mallotus villosus (capelin) and Uria spp. (murre). Descriptive statistics for data aggregated at a scale of $9260 \mathrm{~m}$. Values for capelin are relative area density. $s_{\mathrm{A}}$ : echo density per square nautical mile $\left(3.43 \mathrm{~km}^{2}\right)$; values for murres are numbers $\mathrm{km}{ }^{-2}$. CV: coefficient of variation

\begin{tabular}{|c|c|c|c|c|c|c|c|c|c|c|}
\hline \multirow{2}{*}{ Year } & \multirow[b]{2}{*}{$\mathrm{n}$} & \multirow[b]{2}{*}{ Mean } & \multirow{2}{*}{$\begin{array}{l}\text { Capelin } \\
\text { CV }\end{array}$} & \multirow[b]{2}{*}{ Skewness } & \multirow[b]{2}{*}{ Range } & \multirow[b]{2}{*}{$\mathrm{n}$} & \multirow[b]{2}{*}{ Mean } & \multirow{2}{*}{$\begin{array}{l}\text { Murre } \\
\text { CV }\end{array}$} & \multirow[b]{2}{*}{ Skewness } & \multirow[b]{2}{*}{ Range } \\
\hline & & & & & & & & & & \\
\hline 1986 & 311 & 2.6 & 3.8 & 7.1 & $0-100$ & 96 & 8.6 & 2.6 & 5.5 & $0-179$ \\
\hline 1987 & 671 & 0.6 & 6.4 & 10.7 & $0-67$ & 157 & 1.7 & 4.9 & 11.8 & $0-100$ \\
\hline 1988 & 1557 & 1.6 & 7.5 & 14.6 & $0-278$ & 132 & 0.6 & 1.7 & 2.7 & $0-6$ \\
\hline 1989 & 664 & 12.0 & 5.2 & 9.5 & $0-898$ & 165 & 2.5 & 4.0 & 6.4 & $0-90$ \\
\hline 1990 & 819 & 14.7 & 10.3 & 20.3 & $0-3807$ & 177 & 1.8 & 3.3 & 7.1 & $0-54$ \\
\hline 1991 & 644 & 218.1 & 3.3 & 5.3 & $0-7061$ & 135 & 2.4 & 1.9 & 2.2 & $0-19$ \\
\hline 1992 & 902 & 231.8 & 4.1 & 6.6 & $0-11174$ & 289 & 1.7 & 2.3 & 3.5 & $0-26$ \\
\hline 1993 & 552 & 79.2 & 1.9 & 2.8 & $0-1005$ & 151 & 8.4 & 4.9 & 10.0 & $0-470$ \\
\hline 1994 & 627 & 4.9 & 4.1 & 8.9 & $0-309$ & 173 & 2.5 & 2.6 & 5.2 & $0-57$ \\
\hline
\end{tabular}



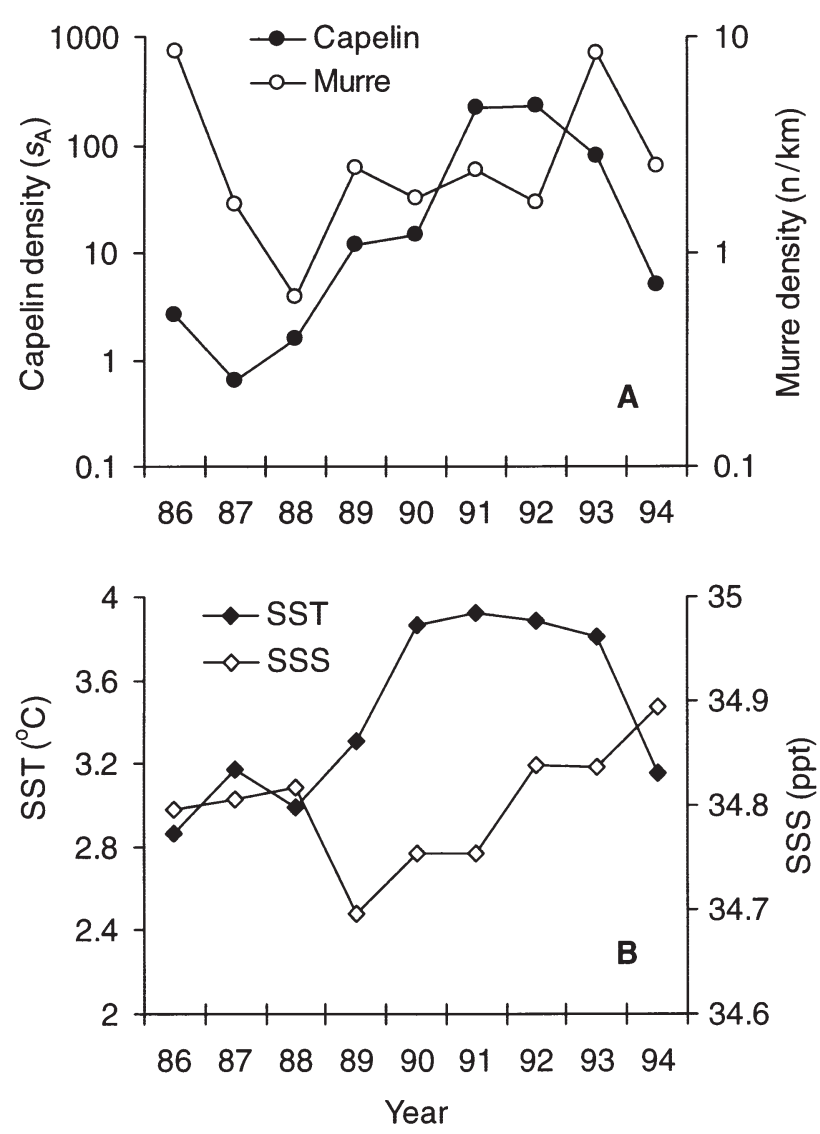

Fig. 2. Mallotus villosus (capelin) and Uria spp. (murre). (A) Yearly density during surveys; capelin density is echo density per square $\mathrm{n}$ mile $\left(s_{\mathrm{A}}\right)$; murre density is number of birds observed per kilometer sailed transect; note logarithmic scale. (B) Mean sea-surface salinity (SSS) and mean sea-surface temperature (SST) in the study area calculated from CTD data obtained from International Council for the Exploration of the Sea (ICES), Copenhagen

Table 1. The distribution of densities of capelin and murres were highly skewed, with a large number of zeroes and a few observations with extremely high values. The mean density of the capelin varied considerably during the $9 \mathrm{yr}$ period (Fig. 2A). Maximum capelin density was found in the 1992 survey with mean $s_{\mathrm{A}}=$ 231.8, while the minimum was found in the 1987 survey with mean $s_{\mathrm{A}}=0.6$. The biomass of the Barents Sea capelin stock was estimated on the basis of surveys made each autumn (Toresen et al. 1998). The mean density of capelin found in this study corresponded well with the total biomass estimates made in the autumn before the surveys $\left(\mathrm{R}^{2}=0.87, \mathrm{n}=9, \mathrm{p}<0.001\right.$, $\log _{10}$-transformed data), and even better with the combined biomass estimates for the autumn before and after the surveys $\left(R^{2}=0.94, n=9, p<0.001, \log _{10}\right.$-transformed data). This indicates that our samples were representative of the Barents Sea capelin stock even though the surveys differed both in length and area covered. The mean densities of murres varied less from year to year compared to the mean densities of capelin (Fig. 2A). The maximum density of murres was found in the 1986 survey, with a mean density of 8.6 birds $\mathrm{km}^{-2}$, and the minimum was found in 1988, with a mean density of 0.6 birds $\mathrm{km}^{-2}$. We found no significant correlation between the mean yearly densities of murres and the mean yearly densities of capelin $\left(R^{2}=\right.$ 0.05, $\mathrm{n}=9, \mathrm{p}=0.55$. The mean SST (Fig. 2B) indicates a large-scale influx of warm Atlantic water in the period 1990 to 1993. This period coincided with high capelin abundance, but no such relationships were found for the murre abundance.

\section{Large-scale analyses}

For all years pooled, we found a large-scale spatial structure of capelin with a characteristic scale of 200 to 300 km; a similar pattern was found for murres (Fig. 3). There was a positive correlation between the $\log _{10}$
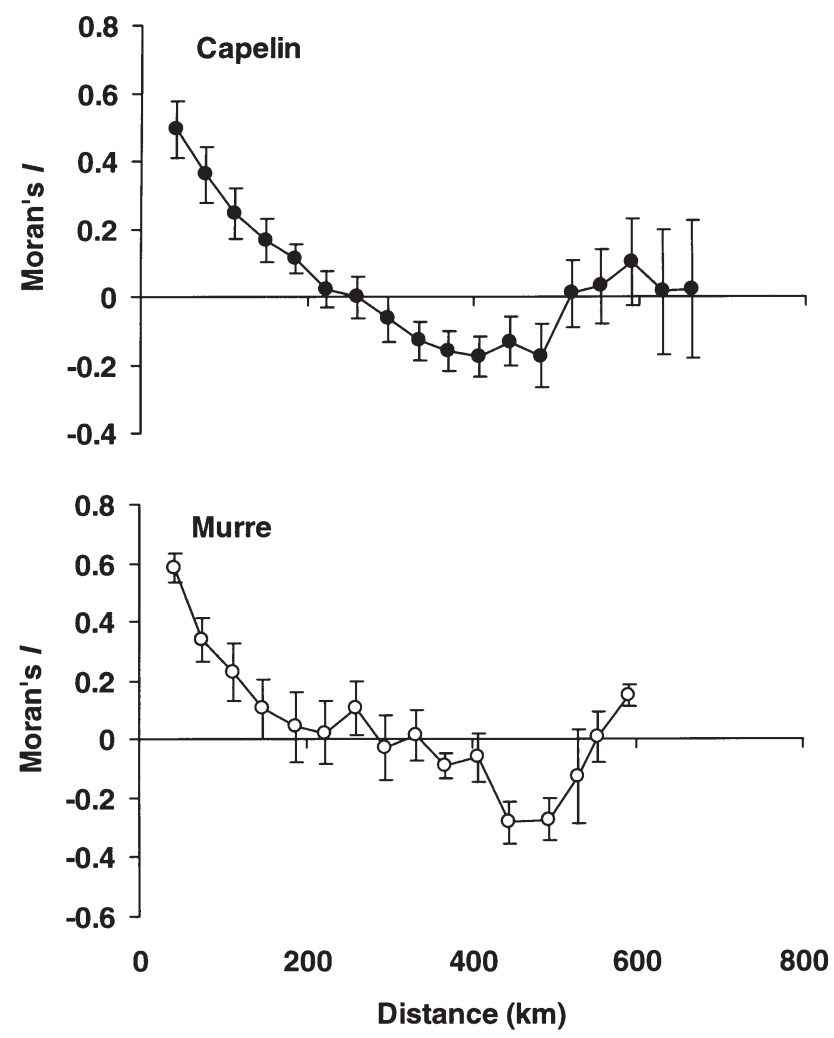

Fig. 3. Mallotus villosus (capelin) and Uria spp. (murre). Large-scale autocorrelation function (mean $\pm \mathrm{SE}$, all years) of the ranked density data. The autocorrelation function gives the correlation (Moran's I) between pairs of observations as a function of spatial distance between the observations. Data were aggregated at a scale of $37 \mathrm{~km}$ 
A

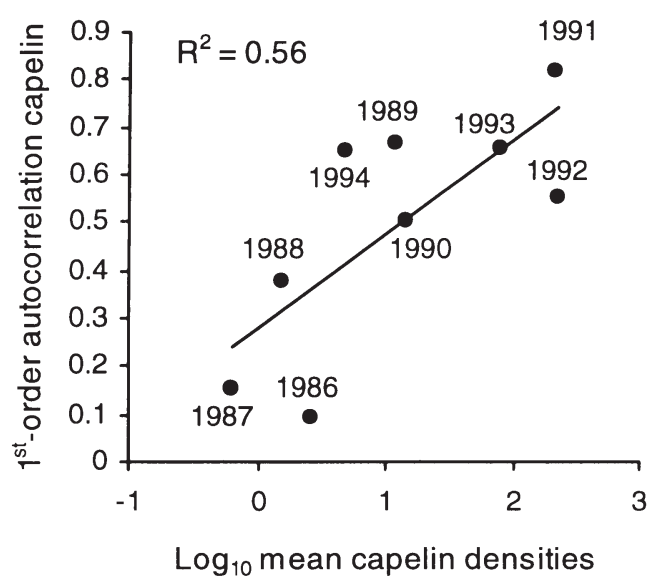

C

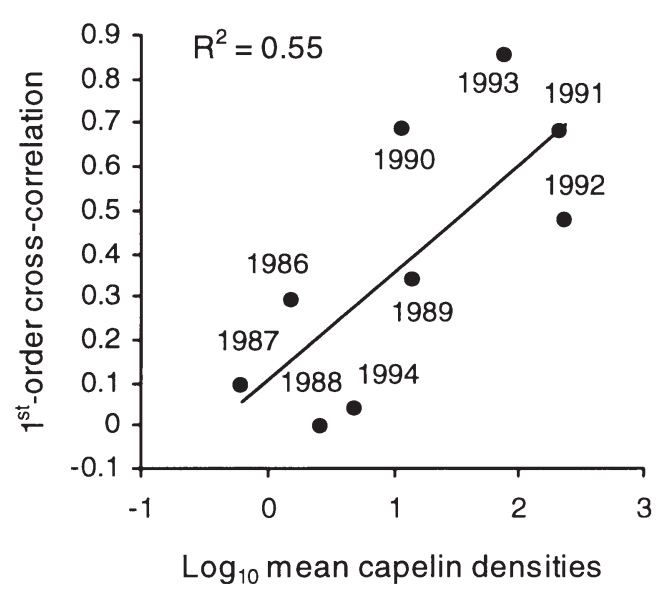

B

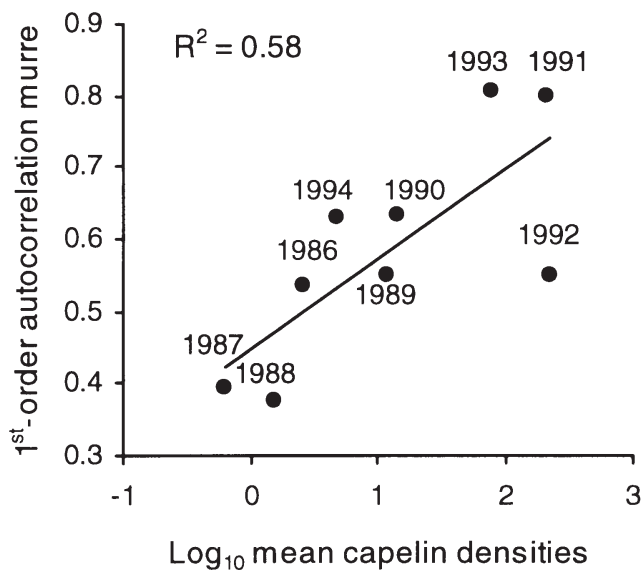

D

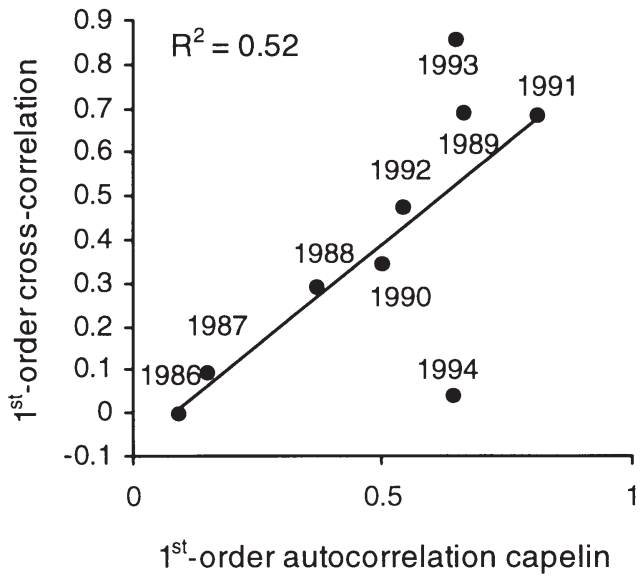

Fig. 4. Mallotus villosus (capelin) and Uria spp. (murre). Large-scale relationships between mean capelin density and capelin patchiness (A), capelin density and murre patchiness (B), capelin density and spatial concordance between murre and capelin (C), and capelin patchiness and spatial concordance between murre and capelin (D). Patchiness is defined as the strength of the first-order autocorrelation (Moran's I), and concordance as the strength of the first-order cross-correlation (Moran's I). Data were aggregated at $37 \mathrm{~km}$ and rank-transformed before analysis. Each data point represents the year indicated

mean density of capelin and the first-order autocorrelation of capelin ( $n=9, p=0.02$, Fig. 4A) and between $\log _{10}$ mean density of capelin and the first-order autocorrelation of murres ( $n=9, p=0.02$, Fig. 4B). Accordingly, the large-scale pattern of both murres and capelin seemed to be more distinct with an increasing density of capelin.

The spatial distribution of capelin together with SSS and SST for 3 years $(1987,1989,1991)$ with low, medium and high capelin densities respectively, are plotted in Fig. 5. Note that 1987 and 1989 were relatively cool years with a low influx of warm Atlantic waters, while 1991 was a relatively warm year with a large influx of Atlantic water (Figs. 2 \& 5). Capelin were found over a relatively large range of SST (0 to $5^{\circ} \mathrm{C}$ ) and $\operatorname{SSS}(34.2$ to $35.1 \mathrm{ppt})$, reflecting the migration through different water masses from the areas around the polar front towards the coast of Norway and Russia. However, capelin were only occasionally found in the warm south-western part of the study area. In 1987, low-density areas with capelin were scattered throughout the survey area, and no largescale structure could be detected by the autocorrelation function. There was no overlap between concentrations of murres and capelin (first-order cross-correlation $=0.09$ ).

In 1989 capelin formed a relatively distinct largescale patch close to the polar front. The autocorrelation function indicated a characteristic scale of about $200 \mathrm{~km}$. The autocorrelation function with respect to murres revealed a similar pattern, and there was a close overlap between murres and capelin (first-order 

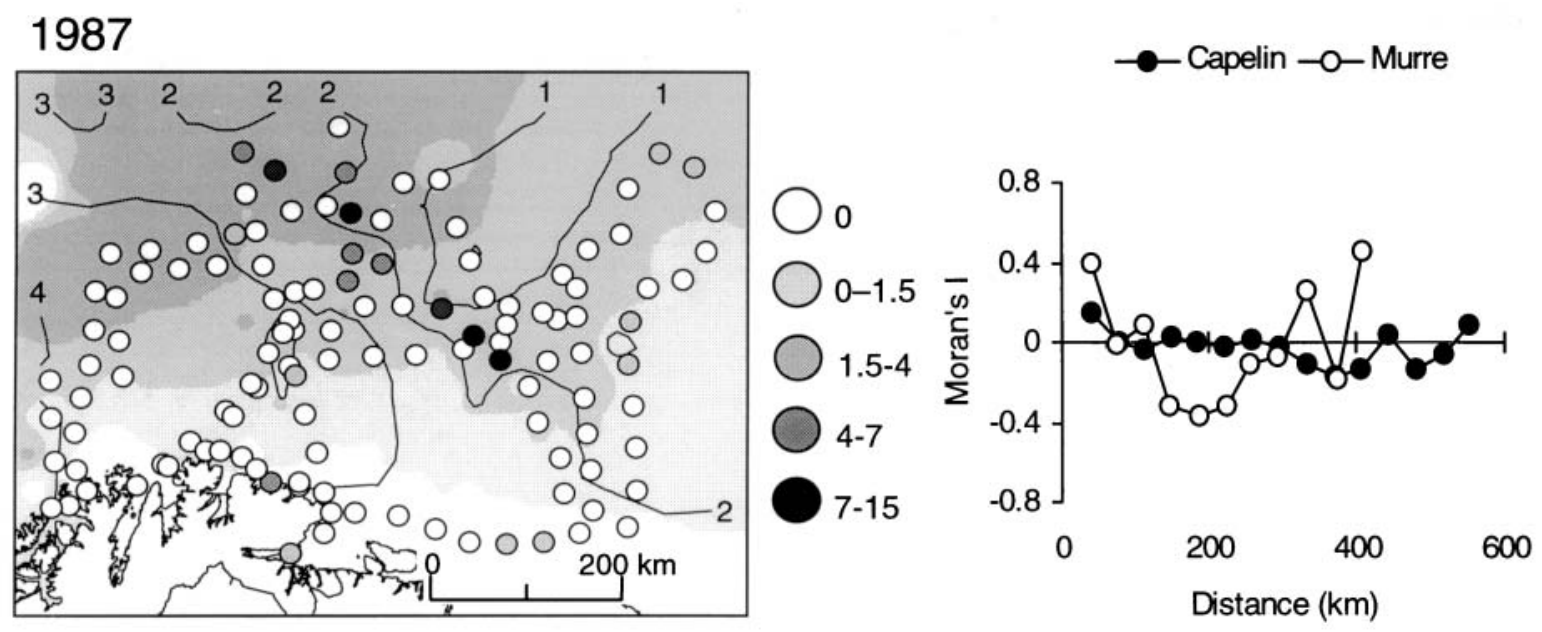

\section{9}
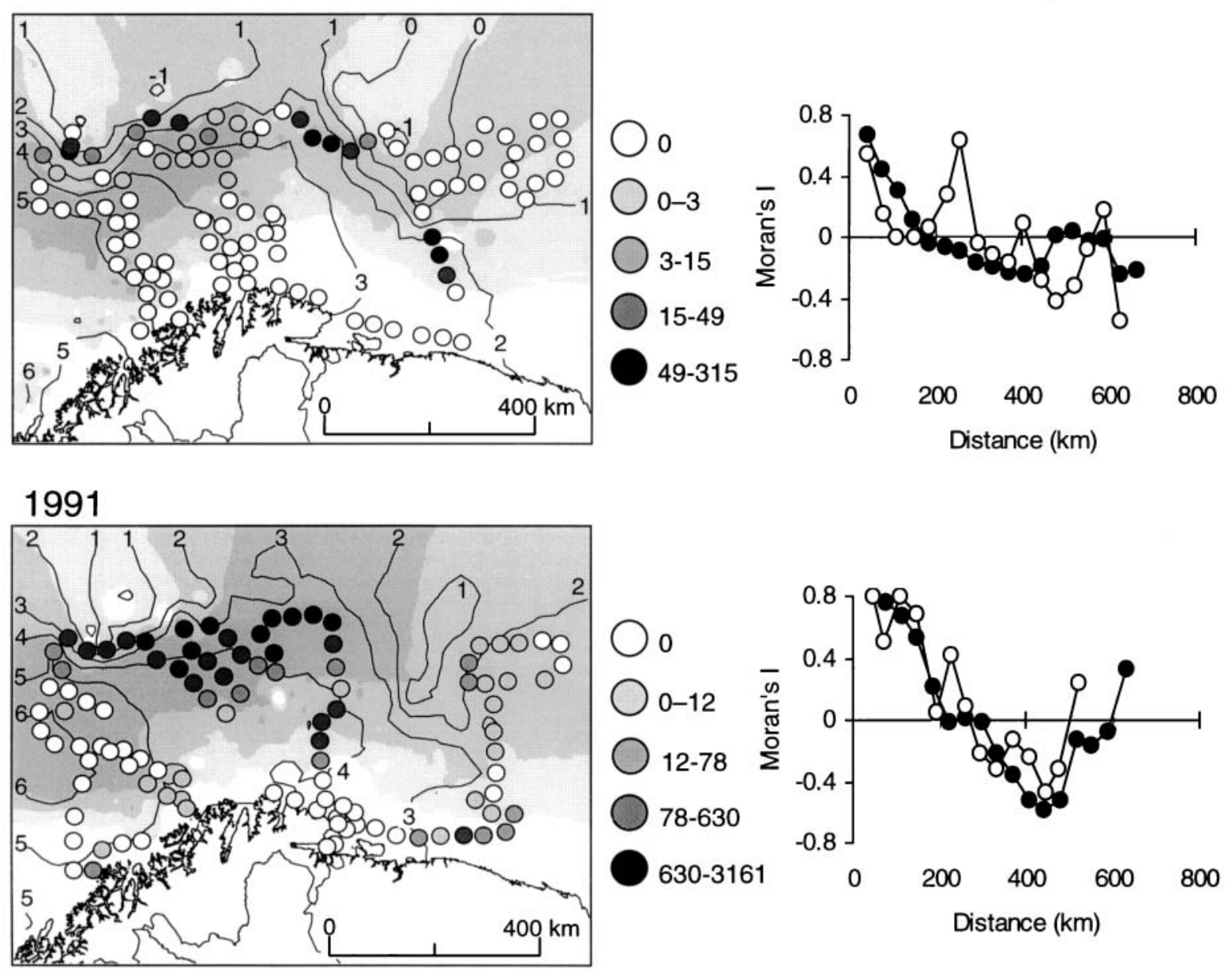

Fig. 5. Mallotus villosus (capelin) and Uria spp. (murre). Large-scale distribution of capelin in relation to sea-surface salinity (SSS) and sea-surface temperature (SST) in 1987, 1989 and 1991 with low, medium and high capelin densities respectively (on left), and corresponding autocorrelation functions for capelin and murre (on right). The first-order cross-correlation between murre and capelin, was 0.09, 0.69 and 0.68 (Moran's I) for 1987, 1989 and 1991 respectively. Capelin and murre data were aggregated at 37 $\mathrm{km}$ and rank-transformed before analysis. The densities of capelin are presented as shaded circles with relative area density $\left(s_{\mathrm{A}}\right)$ values indicated. SSS is plotted as interpolated surface maps with white areas representing SSS $<34.5$ ppt, light gray $34.5<$ SSS $<34.7$ ppt, medium gray $34.7<$ SSS < 34.9 ppt and dark gray SSS > 34.9 ppt. SST is plotted as interpolated isocline maps with temperature $\left({ }^{\circ} \mathrm{C}\right)$ indicated 


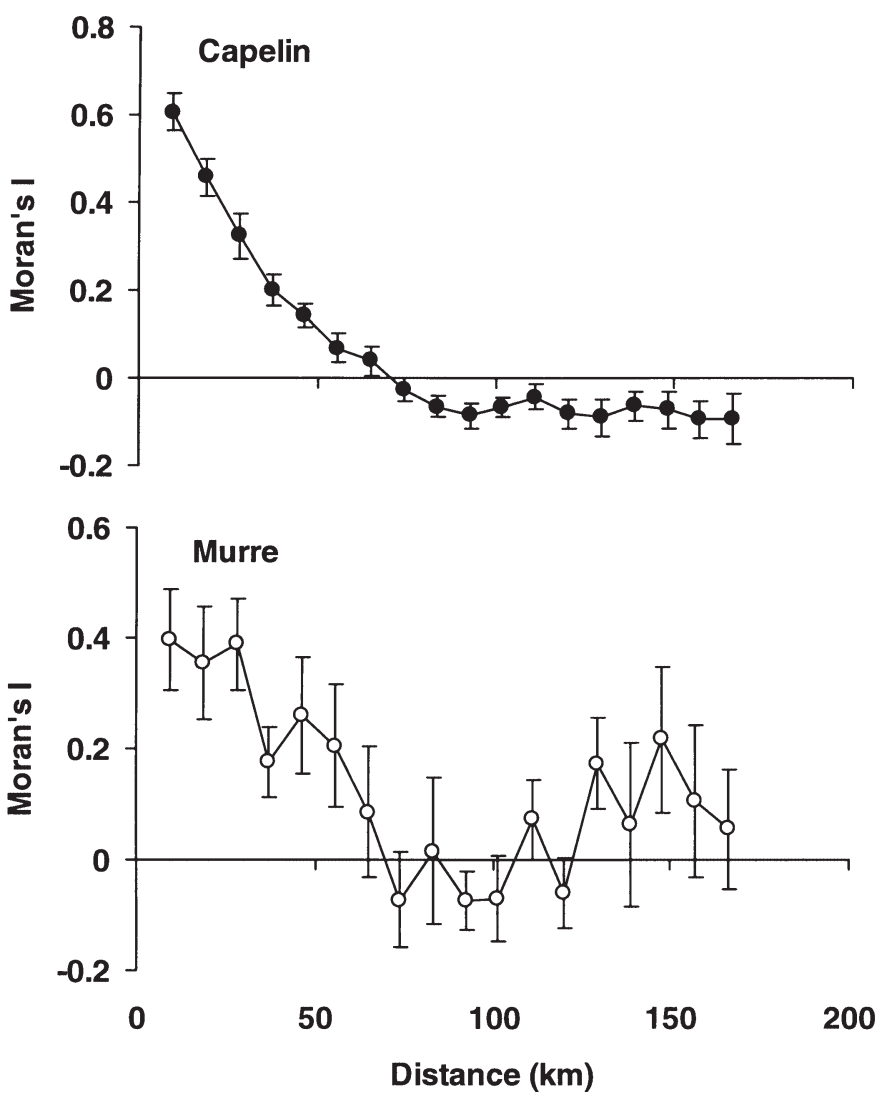

Fig. 6. Mallotus villosus (capelin) and Uria spp. (murre). Small-scale autocorrelation function (mean $\pm \mathrm{SE}$, all years) of the ranked density data nested within the large-scale spatial structures of capelin (see 'Results'). The autocorrelation function gives the correlation (Moran's I) between pairs of observations as a function of spatial distance between the observations. Data were aggregated at a scale of $9260 \mathrm{~m}$

cross-correlation $=0.69$ ). In 1991, a distinct large-scale capelin structure was found close to the polar front. The autocorrelation function revealed a patch structure with a characteristic scale of $200 \mathrm{~km}$. The autocorrelation function with respect to murres was almost identical, and there was a close overlap between murres and capelin (first-order cross-correlation $=0.68$ ).

The capelin structures were generally much longer in the west-east direction than in the south-north direction. Because transects ran mainly south-north, and because the large-scale structures were seldom entirely covered by the surveys, the characteristic scales of large-scale structures revealed by the autocorrelation functions are probably under-estimated.

The large-scale cross-correlation increased significantly with $\log _{10}$ mean capelin density $(n=9, p=0.02$, Fig. 4C). Accordingly, the overlap between concentrations of murres and capelin increased with increasing capelin density. However, the cross-correlation also increased with an increasing first-order capelin auto- correlation ( $n=9, p=0.03$, Fig. 4D). Due to the covariance between capelin density and spatial pattern, it was impossible to disentangle their effects upon the aggregative response of murres.

\section{Small-scale analyses}

We explored the small-scale structures of capelin and murres within the large-scale capelin structures with data aggregated at the highest resolution (9260 m).

Note that we found 2 separate capelin structures in 1993. These structures were separated by a time lag of $10 \mathrm{~d}$, and the last structure had a more southward position (see Fauchald et al. 2000). As a consequence, these structures are treated as independent observations. Moreover, the sample size with respect to murres was too low to allow spatial analyses of murres in 1 of the patches.

The pooled autocorrelograms for all years are shown in Fig. 6. Generally, capelin and murre structures had a characteristic scale of about $70 \mathrm{~km}$. There was a tendency of increasing capelin first-order autocorrelation for increased capelin densities $\left(\mathrm{R}^{2}=0.34, \mathrm{n}=10, \mathrm{p}=\right.$ 0.08, Fig. 7A). When 1991 was removed (Cook's distance $=1.2$; see SAS Institute Inc. 1990 for a definition of Cook's distance), the correlation became highly significant ( $\mathrm{n}=9, \mathrm{p}<0.001$, Fig. 7A). We could not detect any correlation between the murre first-order autocorrelation and capelin densities $\left(R^{2}=0.18, n=9, p=0.25\right.$, Fig. 7B).

The small-scale spatial distribution of capelin and the autocorrelation function with respect to murres and capelin are plotted for 1987, 1989 and 1991 in Fig. 8. In the low-density year (1987), we found distinct capelin patches with a characteristic scale of about $50 \mathrm{~km}$ and a weak overlap between murres and capelin (first-order cross-correlation $=0.26$ ). In the mediumdensity year (1989), the capelin pattern seemed to be more distinct, with a characteristic scale of about 50 to $60 \mathrm{~km}$. The autocorrelation function with respect to murres was similar to that found for capelin. Cross-correlation revealed a close overlap between murres and capelin (first-order cross-correlation $=0.55$ ). In the high-density year (1991), the small-scale structure of capelin became less distinct. Furthermore, we found no structures with respect to murres, and no overlap between murres and capelin (first-order cross-correlation $=0.04$ ). Note that 1991 was a year with an exceptionally low first-order capelin autocorrelation in the light of the high total capelin density.

We could not detect any correlation between the $\log _{10}$ capelin density and the first-order cross-correlation $\left(\mathrm{R}^{2}=0.18, \mathrm{n}=10, \mathrm{p}=0.23\right.$, Fig. $\left.7 \mathrm{C}\right)$. Accordingly, there was no significant increase in the overlap 
A

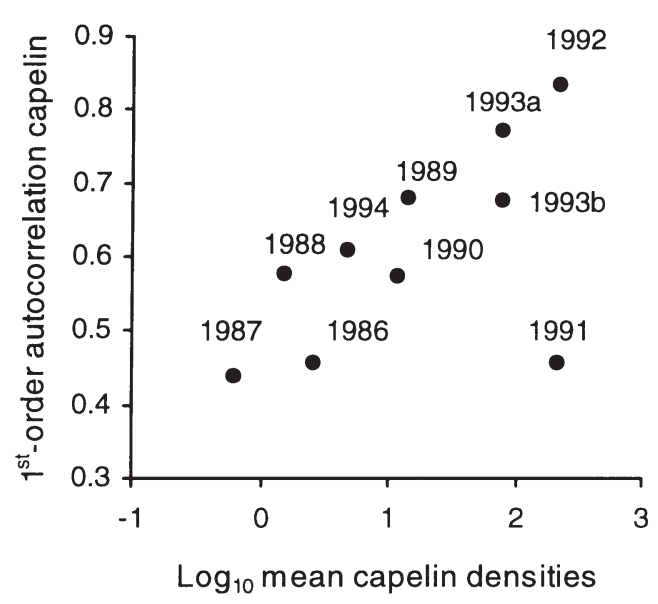

C

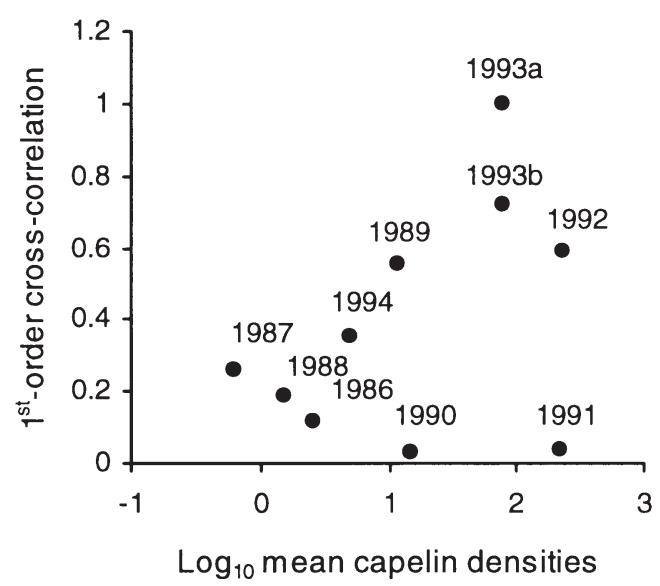

B

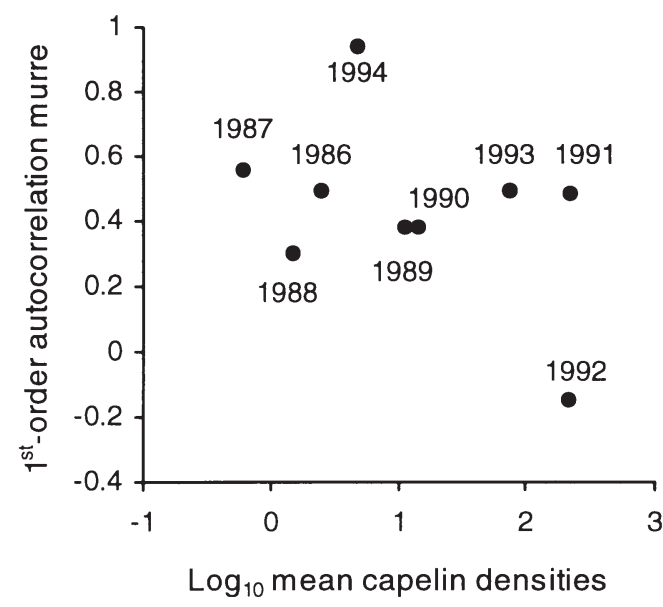

D

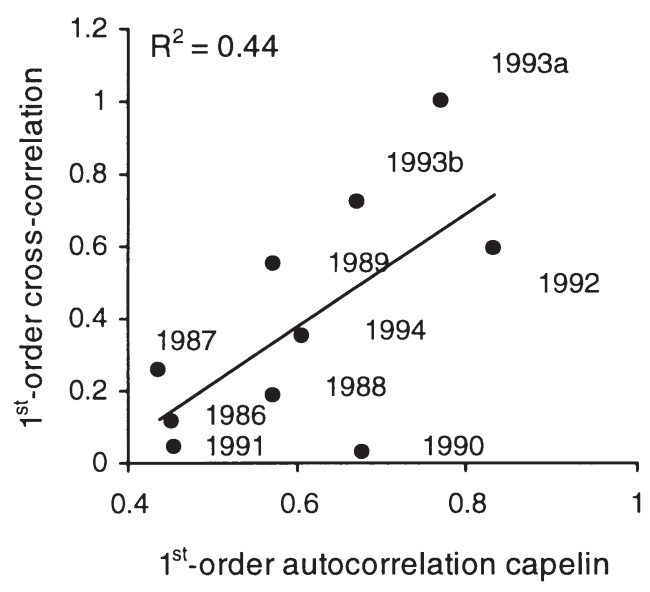

Fig. 7. Mallotus villosus (capelin) and Uria spp. (murre). Small-scale relationships between mean capelin density and capelin patchiness (A), capelin density and murre patchiness (B), capelin density and spatial concordance between murres and capelin (C), and capelin patchiness and spatial concordance between murres and capelin (D). Patchiness is defined as the strength of the first-order autocorrelation (Moran's I), and concordance as the strength of the first-order cross correlation (Moran's I). Data were aggregated at $9260 \mathrm{~m}$ and rank-transformed before analysis. Each data point represents 1 large-scale capelin structure (years are indicated)

between murres and capelin for increased capelin densities. However, we found a positive correlation between the first-order capelin autocorrelation and first-order cross-correlation ( $\mathrm{n}=10, \mathrm{p}=0.04$, Fig. 7D). This indicates that capelin patchiness rather than capelin density influenced the spatial overlap between murres and capelin at the small-scale level.

\section{DISCUSSION}

Generally, the spatial distribution of both murres and capelin in the Barents Sea could be described by a hierarchical patch structure. Large-scale patches generally had a characteristic scale of more than $200 \mathrm{~km}$.
Within the large-scale patches, we found small-scale patches with a characteristic scale of about $70 \mathrm{~km}$. These 2 levels of patchiness corresponded with the large-scale $(300 \mathrm{~km})$ and medium-scale $(50 \mathrm{~km})$ levels found in the 1993 survey by Fauchald et al. (2000). As a consequence of the low resolution of the capelin data we were unable to explore patchiness at smaller spatial scales. The characteristic scale of the patches seemed to be relatively constant from year to year. However, both capelin patchiness defined as the strength of the first-order autocorrelation and total density varied considerably between years, affecting the aggregative response of murres.

At the large scale, capelin patchiness, murre patchiness and the overlap between capelin and murres 
increased with increasing capelin density. In years with low capelin densities, capelin were found scattered throughout the study area. Consequently only weak large-scale structures of capelin could be de- tected, and, moreover, there was a low concordance between densities of murres and capelin. On the other hand, in years of high capelin densities, we found more distinct large-scale capelin and murre patches, and a

1987
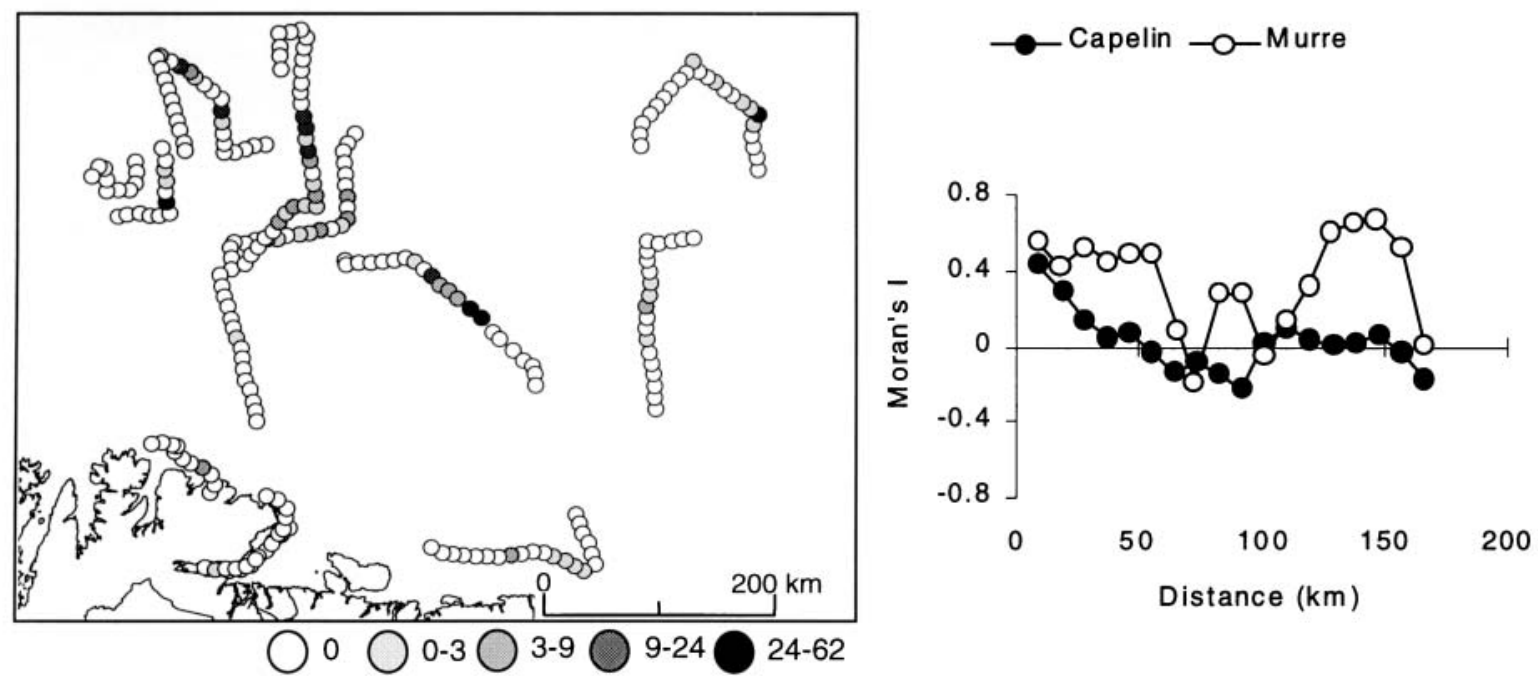

1989

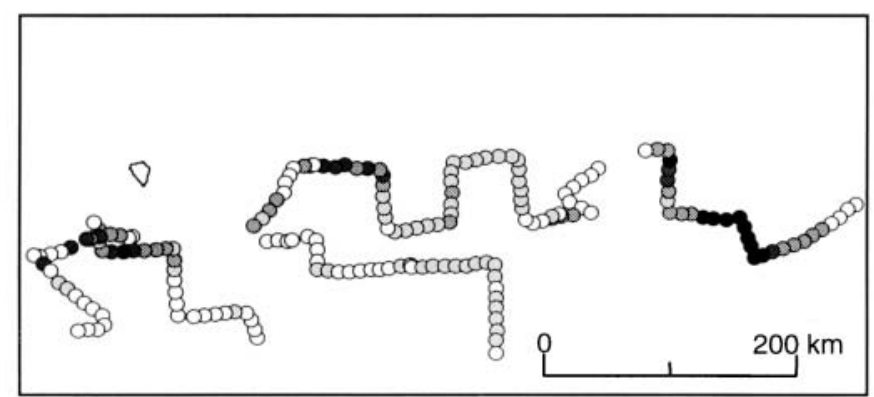

$\bigcirc 0 \bigcirc 0-5 \bigcirc \bigcirc^{5-31} \bigcirc^{31-99} \bigcirc^{99-999}$

1991
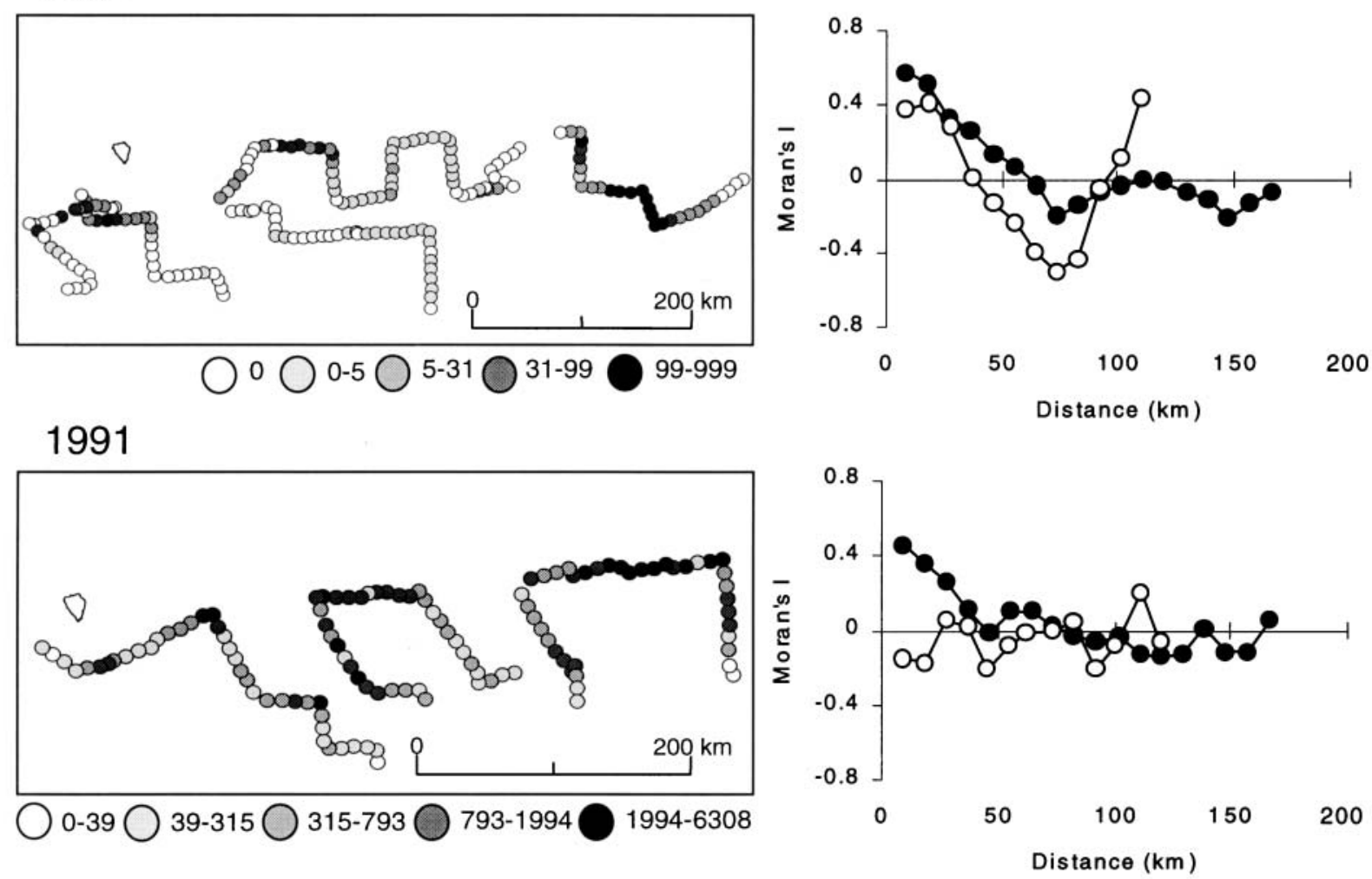

Fig. 8. Mallotus villosus (capelin) and Uria spp. (murre). Small-scale distribution of capelin within the defined large-scale structures from 1987, 1989 and 1991 with low, medium and high capelin densities respectively (on left), and corresponding autocorrelation functions for capelin and murres (on right). The first-order cross-correlation between murres and capelin was $0.26,0.55$ and 0.04 (Moran's I) for 1987, 1989 and 1991 respectively. Capelin and murre data were aggregated at scale of $9260 \mathrm{~m}$ and rank-transformed before analysis. The densities of capelin are presented as shaded circles with relative area density $\left(s_{\mathrm{A}}\right)$ values indicated 
close overlap between murres and capelin. As a consequence of the covariance between capelin patchiness and capelin density, it was impossible to sort out which of the two had the largest impact on the aggregative response of murres.

At the small scale we found, similar to the large-scale analyses, that capelin patchiness tended to increase with increasing capelin density. This correlation was however not significant $(\mathrm{p}=0.08)$. We found no significant correlation between murre patchiness and capelin density or between capelin density and the aggregative response of murres. Instead, the aggregative response of murres increased with increasing capelin patchiness, indicating that capelin patchiness was the major factor determining the concordance between murres and capelin. The analyses at the small scale were strongly influenced by the 1991 observations: 1991 was a year with low small-scale capelin patchiness and high capelin density, and we found no overlap between murres and capelin. The lack of overlap at the small scale in this year might have been a result of predator satiation and consequently reduced search effort (e.g. Murdoch \& Oaten 1975). However, 1992 and 1993 were years with comparable high capelin densities, and in these years both the capelin patchiness and the overlap between murres and capelin were strong.

In this study we found a close covariance between capelin abundance and patchiness. When capelin abundance was low, there was probably not enough capelin to 'fill up' the large-scale patches, and the possibilities of detecting patchiness at the large scale were consequently low. This effect should be reduced at smaller scales. However, we found the same tendency of increased patchiness for increased general capelin density also at the small-scale level. This contradicts the ideal free distribution (IFD) theory (Fretwell \& Lucas 1969, Sutherland 1983). When capelin density was high, we would have expected more severe competition within the small-scale patches, and consequently more capelin should have been found outside the patches, resulting in reduced patchiness. This indicates that competition might be a minor factor determining the spatial distribution of capelin during the spawning migration. One possible explanation for the observed pattern might be that the individual risk of predation decreases with increased patchiness at high densities, while at low densities the individual risk of predation decreases with increased patchiness.

Using a model of optimal foraging in a stochastic hierarchical patch system, Fauchald (1999) concluded that the search efficiency of a predator should increase with increasing prey patchiness and prey abundance. The observed variation in the concordance between murres and capelin does not necessarily reflect the search efficiency of murres. This is because the concordance reflects both the search efficiency of predators and the proportion of predators actually foraging on the specific prey item. However, we expect these mechanisms to be interrelated and scale-dependent. At a large scale, we expect predators to be generally associated with their prey (e.g. Rose \& Leggett 1990). Accordingly, we suggest that the large-scale concordance between murres and capelin indicates the proportion of murres actually foraging on capelin, and hence the profitability of capelin relative to other prey items. On the other hand, within the large-scale structures of capelin, we suggest that the small-scale concordance between murres and capelin reflects the search efficiency of murres relative to the escape abilities of capelin (e.g. Sih 1984, Rose \& Leggett 1990). Generally, capelin patchiness seemed to increase with increasing capelin abundance. Accordingly, the spatial distribution of capelin was more structured under high abundance, possibly increasing the search efficiency of murres. We therefore propose that when capelin abundance was low, murres found it difficult to find sufficient capelin concentrations and, as a consequence, switched to other prey items. The effect of capelin patchiness on murre search efficiency is further supported by the fact that capelin patchiness was the major factor explaining the concordance at the small scale.

A number of studies have suggested that seabirds generally aggregate in areas where oceanographic conditions tend to increase the densities of prey (e.g. Decker \& Hunt 1996, Hunt et al. 1998, Mehlum et al. 1998, Russell et al. 1999). Most studies on these relationships have been done during the breeding period, when the birds are limited by their duties in the colony (Hunt et al. 1999). For example, in a study from the Bering Sea, Decker \& Hunt (1996) found elevated densities of murres in frontal regions, but no significant relationship between murres and acoustically determined biomass. They proposed that murres restricted their foraging to frontal regions because prey can be located more predictably within these areas. Similarly, Mehlum et al. (1998) found a close relationship between murres breeding at Bjørnøya in the Barents Sea and the polar front. During the spawning migration of capelin in the Barents Sea, the maturing fish migrate through a spectrum of different oceanographic conditions from polar front water-masses through more Atlantic waters and finally spawn in coastal waters. During this period murres are not restricted by activities in the breeding colony and may actively follow the migration of prey. The timing and general climate of the Barents Sea might give some clues as to where to find the large-scale capelin patches (Gjøsæter 1998). However, we suggest that in years when murres 
actively foraged on capelin, they tracked capelin patches along the migration path, possibly using a hierarchical search strategy (Russell et al. 1992, Fauchald 1999, Fauchald et al. 2000). In the years of low concordance between murres and capelin, however, murres might have used a more opportunistic strategy by visiting spatially predictable areas where specific oceanographic features increase the possibility of finding prey. This suggests that in certain periods murres may track highly profitable prey items such as capelin with a more or less unpredictable and dynamic spatial distribution, while in other periods they may switch to become a generalist preying on a diverse group of prey that are either passively or actively congregated in predictable areas with specific oceanographic features. Studies on the diet of murres in the Barents Sea during the breeding period have indeed shown a diverse group of prey items (Barrett et al. 1997), indicating that murres may utilize a large range of prey items. In a study on the diet of seabirds collected in the Barents Sea during winter 1987, Erikstad (1990) found a diverse diet consisting of cod, polar cod Boreogadus saida, redfish Sebastes spp. and crustaceans in the stomach of 24 thick-billed murres. The murres collected were relatively lean, indicating that low capelin abundance and switching to other prey items might involve an energetic cost. When alternative prey is scarce, a low abundance of capelin will have detrimental effects upon murres. Indeed, the crash in the capelin stock in the mid-1980s was probably a major factor causing mass starvation and breeding failure of common murres in the area, while thickbilled murres were relatively unaffected (Vader et al. 1990). However, switching to other prey items also suggests that the proportional predation on capelin in the years of low capelin abundance was low, resulting in a stabilizing predator-prey interaction (e.g. Murdoch \& Oaten 1975).

In conclusion, we have demonstrated a close relationship between capelin abundance, capelin patchiness and the aggregative response of murres in the Barents Sea. Both capelin patchiness and the aggregative response of murres decreased with decreasing capelin abundance. As suggested by Fauchald (1999), both reduced patchiness and abundance might reduce the search efficiency of a predator foraging in a stochastic hierarchical patch system. With respect to capelin, both factors work in concert and may therefore force predators to switch to other prey items under low capelin abundance.

Acknowledgements. We are grateful for the help and cooperation of the captain, crew and scientists on board RV 'Johan Hjort' and 'G. O. Sars'. We thank the Norwegian Institute of Marine Research for letting us use their acoustic data on capelin, and Vidar Bakken, Tor-Harry Bjørn, Jan Ove
Bustnes, Karl-Otto Jacobsen, Halvar Ludvigsen and Hege Skarsfjord for help with bird observations. Thanks to Torkild Tveraa, Nigel G. Yoccoz and 3 anonymous referees for helpful comments on earlier drafts, and Rob Barrett for improving the English. The study was partly financed by the Research Council of Norway and the Working Group of Environmental Impact Assessments of Petroleum Activities on the Norwegian Continental Shelf (AKUP).

\section{LITERATURE CITED}

Aebischer NJ, Coulson JC, Colebrook JM (1990) Parallel long-term trends across four marine trophic levels and weather. Nature 347:753-755

Anker-Nilssen T (1992) Food supply as a determinant of reproduction and population development in Norwegian Puffins Fratercula arctica. Dissertation, University of Trondheim

Anonymous (1997) Report of the northern pelagic and blue whiting fisheries working group. ICES Counc Meet Pap 14

Barrett RT, Bakken V, Krasnov JV (1997) The diets of common and Brünnich's guillemots Uria aalge and U. lomvia in the Barents Sea region. Polar Res 16:73-84

Belopol'skii LO (1957) Ecology of sea colony birds of the Barents Sea (English translation 1961; Israel Program for Scientific Translation, Jerusalem)

Burger AE, Simpson M (1986) Diving depths of Atlantic puffins and common murres. Auk 103:828-830

Chastel O, Weimerskirch H, Jouventin P (1993) High annual variability in reproductive success and survival of an Antarctic seabird, the snow petrel Pagodroma nivea. Oecologia 94:278-284

Decker MB, Hunt GL Jr (1996) Foraging by murres (Uria spp.) at tidal fronts surrounding the Pribilof Islands, Alaska, USA. Mar Ecol Prog Ser 139:1-10

Erikstad KE (1990) Winter diets of four seabird species in the Barents Sea after a crash in the capelin stock. Polar Biol 10:619-627

Erikstad KE, Vader W (1989) Capelin selection by Common and Brünnich's Guillemots during the prelaying season. Ornis Scand 20:151-155

Erikstad KE, Moum T, Vader W (1990) Correlations between pelagic distribution of Common and Brünnich's Guillemots and their prey in the Barents Sea. Polar Res 8:77-87

Fauchald P (1999) Foraging in a hierarchical patch system. Am Nat 153:603-613

Fauchald P, Erikstad KE, Skarsfjord H (2000) Scale dependent predator-prey interactions: the hierarchical spatial distribution of seabirds and prey. Ecology 81:773-783

Fretwell SD, Lucas HL Jr (1969) On territorial behavior and other factors influencing habitat distribution in birds. Acta Biotheor 19:16-36

Furness RW, Barrett RT (1985) The food requirements and ecological relationships of a seabird community in North Norway. Ornis Scand 16:305-313

Gjøsæter H (1998) The population biology and exploitation of capelin (Mallotus villosus) in the Barents Sea. Sarsia 83: 453-496

Gjøsæter H, Bogstad B (1998) Effects of the presence of herring (Clupea harengus) on the stock-recruitment relationship of Barents Sea capelin (Mallotus villosus). Fish Res (Amst) 38:57-71

Guinet C, Chastel O, Koudil M, Durbec JP, Jouventin P (1998) Effects of warm sea-surface temperature anomalies on the blue petrel at the Kerguelen Islands. Proc R Soc Lond Ser B Biol Sci 265:1-6 
Hamre J (1994) Biodiversity and exploitation of the main fish stocks in the Norwegian-Barents Sea ecosystem. Biodiv Conserv 3:473-492

Hassell KP, May RM (1973) Stability in insect host-parasite models. J Anim Ecol 42:693-726

Hassell KP, May RM (1974) Aggregation of predators and insect parasites and its effect on stability. J Anim Ecol 43: 567-594

Heinemann D, Hunt G, Everson I (1989) Relationships between the distributions of marine avian predators and their prey, Euphausia superba, in the Bransfield Strait and southern Drake Passage, Antarctica. Mar Ecol Prog Ser $58: 3-16$

Hunt GL Jr (1990) The pelagic distribution of marine birds in a heterogeneous environment. Polar Res 8:43-54

Hunt GL Jr, Russell RW, Coyle KO, Weingartner T (1998) Comparative foraging ecology of planktivorous auklets in relation to ocean physics and prey availability. Mar Ecol Prog Ser 167:241-259

Hunt GL Jr, Mehlum F, Russell RW, Irons D, Decker MB, Becker PH (1999) Physical processes, prey abundance, and the foraging ecology of seabirds. In: Adams NJ, Slotow RH (eds) Proc 22nd Int Ornithol Congr, Durban. Bird Life South Africa, Johannesburg, p 2040-2056

Huse G, Toresen R (2000) Juvenile herring prey on Barents Sea capelin larvae. Sarsia 85:385-391

Kotliar NB, Wiens JA (1990) Multiple scales of patchiness and patch structure: a hierarchical framework for the study of heterogeneity. Oikos 59:253-260

Legendre P, Fortin MJ (1989) Spatial pattern and ecological analysis. Vegetatio 80:107-138

Loeng H (1989) Ecological features of the Barents Sea. In: Rey L, Alexander V (eds) Proc 6th Conf Comité Arctique International, 1985. E J Brill, Leiden, p 327-365

Logerwell EA, Hargreaves NB (1996) The distribution of seabirds relative to their fish prey off Vancouver Island: opposing results at large and small spatial scales. Fish Oceanogr 5:163-175

MacLennan DN, Simmonds EJ (1992) Fisheries acoustics. Chapman \& Hall, London

Maravelias CD, Reid DG, Simmonds EJ, Haralabous J (1996) Spatial analysis and mapping of acoustic survey data in the presence of high local variability: geostatistical application to North Sea herring (Clupea harengus). Can J Fish Aquat Sci 53:1497-1505

Mehlum F, Nordlund N, Isaksen K (1998) The importance of the 'Polar Front' as a foraging habitat for guillemots Uria spp. breeding at Bjørnøya, Barents Sea. J Mar Syst 14: $27-43$

Mehlum F, Hunt GL Jr, Klusek Z, Decker MB (1999) Scaledependent correlations between the abundance of Brünnich's guillemots and their prey. J Anim Ecol 68:60-72

Monaghan P, Walton P, Wanless S, Uttley JD, Burns MD (1994) Effects of prey abundance on the foraging behavior, diving efficiency and time allocation of breeding guillemots Uria aalge. Ibis 136:214-222

Montevecchi WA, Myers RA (1997) Centurial and decadal oceanographic influences on changes in northern gannet populations and diets in the north-west Atlantic: implications for climate change. ICES J Mar Sci 54:608-614

Murdoch WW, Oaten A (1975) Predation and population stability. Adv Ecol Res 9:2-131

Editorial responsibility: Otto Kinne (Editor),

Oldendorf/Luhe, Germany
Murdoch WW, Oaten A (1989) Aggregation by parasitoids and predators: effects on equilibrium and stability. Am Nat 134:288-310

Murphy EJ, Morris DJ, Watkins JL, Priddle J (1988) Scales of interactions between Antarctic krill and the environment. In: Sahrhage D (ed) Antarctic ocean and resources variability. Springer-Verlag, Berlin, p 120-130

Obst BS (1985) Densities of Antarctic seabirds at sea and the presence of the krill Euphausia superba. Auk 102:540-549

Pakhomov EA, McQuaid CD (1996) Distribution of surface zooplankton and seabirds across the Southern Ocean. Polar Biol 16:271-286

Piatt JF (1990) The aggregative response of common murres and Atlantic puffins to schools of capelin. Stud Avian Biol $14: 36-51$

Piatt JF, Nettleship DN (1985) Diving depths of four alcids. Auk 102:293-297

Rose GA, Leggett WC (1990) The importance of scale to predator-prey spatial correlations: an example of Atlantic fishes. Ecology 71:33-43

Russell RW, Hunt GL Jr, Coyle KO, Cooney RT (1992) Foraging in a fractal environment: spatial patterns in a marine predator-prey system. Landsc Ecol 7:195-209

Russell RW, Harrison NM, Hunt GL Jr (1999) Foraging at a front: hydrography, zooplankton, and avian planktivory in the northern Bering Sea. Mar Ecol Prog Ser 182:77-93

Ryan PG, Cooper J (1989) The distribution and abundance of aerial seabirds in relation to Antarctic krill in the Prydz Bay Region, Antarctica, during late summer. Polar Biol 10: 199-209

SAS Institute Inc. (1990) SAS/STAT user's guide. Release 6.04 edn. SAS Institute Inc, Cary, NC

Schneider DC, Piatt JP (1986) Scale-dependent correlation of seabirds with schooling fish in a coastal ecosystem. Mar Ecol Prog Ser 32:237-246

Schreiber RW, Schreiber EA (1984) Central Pacific seabirds and the El Niño southern oscillation: 1982 to 1983 perspectives. Science 225:713-716

Sih A (1984) The behavioral response race between predator and prey. Am Nat 123:143-150

Sutherland WJ (1983) Aggregation and the 'ideal free distribution'. J Anim Ecol 52:821-828

Toresen R, Gjøsæter H, deBarros P (1998) The acoustic method as used in the abundance estimation of capelin (Mallotus villosus Müller) and herring (Clupea harengus Linné) in the Barents Sea. Fish Res (Amst) 34:27-37

Uttley JD, Walton P, Monaghan P, Austin G (1994) The effects of food abundance on breeding performance and adult time budgets of guillemots Uria aalge. Ibis 136:205-213

Vader W, Barrett RT, Erikstad KE, Strann KB (1990) Differential responses of common and thick-billed murres to a crash in the capelin stock in the southern Barents Sea. Stud Avian Biol 14:175-180

Veit RR, Silverman ED, Everson I (1993) Aggregation patterns of pelagic predators and their principal prey, Antarctic krill, near South Georgia. J Anim Ecol 62:551-564

Veit RR, Pyle P, McGowan JA (1996) Ocean warming and long-term change in pelagic bird abundance within the California current system. Mar Ecol Prog Ser 139:11-18

Woodby DA (1984) The April distribution of murres and prey patches in the southeastern Bering Sea. Limnol Oceanogr 29:181-188

Submitted: April 25, 2001; Accepted: October 16, 2001

Proofs received from author(s): March 27, 2002 